\title{
Biopolítica do saudável e a controversa tentativa de revisão do Guia Alimentar para a População Brasileira ${ }^{1}$
}

\author{
Lucas de Vasconcelos Teixeira' \\ https://orcid.com/0000-0002-3890-0747
}

\section{Tânia Márcia Cezar Hoff'}

https://orcid.com/0000-0002-3619-034X

I - Escola Superior de Propaganda e Marketing. São Paulo (SP). Brasil.

Resumo: O que se come e o que se bebe é algo bastante debatido na atualidade. De um lado, temos os entusiastas da alimentação natural, que evitam comida processada e abominam os ultraprocessados. De outro, há os defensores dos alimentos processados e ultraprocessados como parte de uma dieta saudável e nutritiva. O objetivo deste artigo é examinar os rastros e captar as mediações em busca das associações criadas pelos e entre os actantes na controvérsia, ocorrida em setembro de 2020, gerada por uma nota técnica do Ministério da Agricultura, Pecuária e Abastecimento (MAPA) sobre revisão do Guia Alimentar para a População Brasileira. Analisamos, também, aspectos biopolíticos que emergem nas disputas em torno da alimentação saudável. São mobilizados autores da comunicação, consumo, alimentação, biopolítica e teoria ator-rede (TAR), tendo como metodologia a cartografia das controvérsias (CC), o que permite analisar os actantes, as mediações e os embates entre essas duas visões de mundo em colisão.

Palavras-chave: consumo alimentar; biopolítica; cartografia das controvérsias; teoria ator-rede. 


\begin{abstract}
Biopolitics of health and the controversial attempt to revise the Food Guide for the Brazilian Population - What you eat and what you drink is quite hotly debated nowadays. On one side, we have the natural food enthusiasts, who avoid processed food and abhor ultra-processed food. On the other, there are the advocates of processed and ultra-processed foods as part of a healthy and nutritious diet. The goal of this paper is to examine the tracks and capture the mediations in search of the associations created by and between the actors in the controversy, that occurred in September 2020, which arose from a technical note from the Ministry of Agriculture, Livestock and Supply (MAPA) revealing this body's plan to revise the Food Guide for the Brazilian Population. We also analyzed the biopolitical aspects arising from the disputes surrounding healthy food. Authors on communication, consumption, food, biopolitics and actor-network theory (ANT) are mobilized, using cartography of controversies (CC) as methodology, which enables the analysis of the actors, mediations and the clashes between these two worldviews.
\end{abstract}

Keywords: food consumption; biopolitics; cartography of controversies; actornetwork theory.

\title{
Introdução
}

A pós-modernidade ocidental, de acordo com Jameson (1985), é vivenciada na cultura, na vida social e também na ordem econômica, recebendo muitas denominações, dentre elas: sociedade pós-industrial, sociedade do consumo, capitalismo multinacional, capitalismo tardio. Segundo Kumar (2006), o período contemporâneo é caracterizado pelo fim das grandes narrativas, pelo ceticismo em relação ao método científico, pela fragmentação/encurtamento do espaço-tempo, pelas tecnologias da informação e globalização exacerbadas. No tocante a esta última característica, observa-se um duplo movimento, posto que a universalização e padronização acontecem simultaneamente à particularização e diversificação.

No que se refere ao campo da alimentação, também observamos este duplo movimento: de um lado, as grandes corporações globais responsáveis por muitos dos alimentos que vemos nas gôndolas de supermercados; de outro, consumo alimentar voltado aos produtos orgânicos, naturais e produzidos localmente. Para Renato Ortiz, o consumo de alimentos revela os agrupamentos sociais e suas regras particulares: "a comida representa simbolicamente os modos dominantes de uma sociedade" (ORTIZ, 2007, p. 77). Atualmente, essa dominância não está estabilizada, o que nos permite analisar o social em tensão - a visibilidade da rede que se dá nas controvérsias antes que congelem em caixas-pretas (LEMOS, 2013; VENTURINI, 2010). Assim, este 
artigo tem como tema a controvérsia do consumo alimentar, no Brasil, entre comida natural e alimento industrialmente processado.

Segundo Lemos (2013), Latour (2012) e Venturini (2010), o momento ideal de análise dos fenômenos sociais é o da controvérsia - o espaço-tempo da associação e da formação do social, o que emerge das associações entre os fenômenos e suas redes de mediadores. Esses são os actantes, o ator da expressão ator-rede. Já a contraparte desse binômio é o próprio movimento associativo, o espaço-tempo: "Rede não é por onde as coisas passam, mas aquilo que se forma na relação (mediação, tradução) das coisas" (LEMOS, 2013, p. 54). Há ainda a noção de intermediário - que transporta sem modificar, sem mediar, sem atuar no espaço-tempo em determinado contexto; de mediadores, que "transformam, traduzem, distorcem e modificam o significado ou os elementos que supostamente veiculam" (LATOUR, 2012, p. 65), ou seja, há uma relação direta entre ação e mediação; e a de caixa-preta - a estabilização de uma controvérsia e a resolução de um problema. Quando os elementos de um processo agem como um só e desaparecem as mediações, restam somente os intermediários. De todo modo, uma controvérsia pode reaparecer

[...] sempre que houver a necessidade de se questionar o que parecia natural ou de recuperar o que havia de problemático em uma rede estabilizada. Trata-se de apontar inconsistências, exigir a inclusão de demandas de um grupo, ou programa de ação que havia sido esquecido etc. Neste caso, a 'cartografia das controvérsias' pode ser aplicada de modo a reconstituir como disputa os dois programas de ação, já que a defesa do objeto disputado implica a mobilização da sua rede para fazer a crítica. As estabilidades serão postas em crise. As caixas-pretas serão abertas, por um lado ou pelo outro. (LEMOS, 2013, p. 89).

Neste artigo, temos como objetivo examinar os rastros e captar as mediações em busca das associações criadas, pelos e entre os actantes, na controvérsia desencadeada em torno do pedido de reformulação do Guia Alimentar para a População Brasileira, por parte do Ministério da Agricultura, Pecuária e Abastecimento (MAPA), em setembro de 2020. Analisamos também os aspectos biopolíticos que emergem nessa disputa midiático-discursiva. Com efeito, investigamos a seguinte questão: de que forma aconteceu o processo de abertura e fechamento da caixa-preta sobre o pedido de reformulação do Guia Alimentar para a População Brasileira? 
Para as reflexões sobre comunicação, consumo, alimentação, biopolítica e teoria ator-rede (TAR) alguns dos autores mobilizados são Sibilia (2015), Prado (2013), Lemos (2013), Latour (2012), Bruno (2012), Rose (2011), Pelbart (2011), Venturini (2010), Ortiz (2007), Rabinow (1999) e Deleuze (1992). corpus analisado é formado pela nota técnica do MAPA que desencadeou a controvérsia, notas de entidades contrárias e favoráveis em resposta ao cogitado pelo ministério, além de mapeamento das interações espontâneas às postagens dessas entidades na rede social Facebook. A cartografia das controvérsias (CC) consiste na metodologia empregada para a análise do corpus.

Nas próximas seções desse artigo, serão abordados os seguintes pontos: panorama geral das disputas no que se refere ao consumo alimentar dos brasileiros; dimensão biopolítica do consumo de alimentos; apresentação da controvérsia alimentar de setembro de 2020; análise dessa controvérsia e considerações finais.

\section{Cartografia do consumo alimentar no Brasil}

A segunda edição do Guia Alimentar para a População Brasileira² foi lançada em novembro de 2014³, sob a égide do Ministério da Saúde. Conforme Reis (2019), o guia tem como pressupostos o direito da população brasileira à saúde e também à alimentação adequada e saudável, configurando-se como um instrumento de apoio às ações de educação alimentar e nutricional realizadas pelas diferentes instâncias do governo e da sociedade civil. Ainda segundo a referida autora, essa atual versão do guia é voltada para o cidadão comum, ao contrário da primeira edição, que era mais técnica e direcionada à consulta de nutricionistas. Outra mudança foi a adoção da escala de processamento dos alimentos em vez do perfil de nutrientes (fontes de carboidratos, proteínas e gorduras) e grupos alimentares (por exemplo, reunindo batata, pães e cereais matinais no mesmo grupo, no caso, fonte de carboidratos), padrão da primeira edição do Guia Alimentar ${ }^{4}$.

A partir de 2009, a escala de processamento dos alimentos, resultante de pesquisas do Núcleo de Pesquisas Epidemiológicas em Nutrição e Saúde

\footnotetext{
2 Segunda edição do Guia Alimentar para a População Brasileira. Disponível em: <https://bvsms.saude. gov.br/bvs/publicacoes/guia_alimentar_populacao_brasileira_2ed.pdf>. Último acesso em: 12 mar. 2021.

3 Disponível em: <https://www.abrasco.org.br/site/noticias/institucional/nova-edicao-do-guia-alimentar-da-populacao-brasileira-valoriza-promocao-da-saude/7634/>. Último acesso em 12 mar. 2021.

4 Primeira edição do Guia Alimentar para a População Brasileira. Disponível em: <https://bvsms.saude. gov.br/bvs/publicacoes/guia_alimentar_populacao_brasileira.pdf>. Último acesso em: 12 mar. 2021.
} 
$(\text { NUPENS) })^{5}$ - sumarizada na tabela 1 -, tem sido debatida por meio de artigos científicos, por exemplo: Monteiro et al. (2010); Santana et al. (2020). Esses estudos deram origem à classificação denominada NOVA, que avalia não somente o conteúdo dos alimentos em nutrientes, mas também atributos com potencial de influenciar o risco de obesidade e de outras doenças relacionadas à alimentação.

\begin{tabular}{|l|l|l|}
\hline Grupos de Alimentos & Forma de processamento & Exemplos \\
\hline $\begin{array}{l}\text { Grupo 1 - in natura } \\
\text { ou minimamente } \\
\text { processados }\end{array}$ & $\begin{array}{l}\text { Alimentos não processados ou com o mínimo } \\
\text { de processamento, como a remoção de partes } \\
\text { não comestíveis ou não desejadas, secagem, } \\
\text { moagem e outros processos similares }\end{array}$ & $\begin{array}{l}\text { legumes, grãos e } \\
\text { frutas }\end{array}$ \\
\hline $\begin{array}{l}\text { Grupo } 2 \text { - ingredientes } \\
\text { culinários processados }\end{array}$ & $\begin{array}{l}\text { Substâncias extraídas de alimentos do } \\
\text { grupo 1 com a utilização de certos tipos } \\
\text { de procedimentos, como centrifugação e } \\
\text { prensagem }\end{array}$ & azeite, sal e açúcar \\
\hline $\begin{array}{l}\text { Grupo 3 - alimentos } \\
\text { processados }\end{array}$ & $\begin{array}{l}\text { Alimentos produzidos com a adição de sal ou } \\
\text { açúcar ou outra substância do grupo 2 a um } \\
\text { alimento do grupo 1 }\end{array}$ & $\begin{array}{l}\text { frutas em calda, } \\
\text { queijos e pães } \\
\text { artesanais }\end{array}$ \\
\hline $\begin{array}{l}\text { Grupo 4 - alimentos } \\
\text { ultraprocessados }\end{array}$ & $\begin{array}{l}\text { Comida ou bebida fabricada com diferentes } \\
\text { tipos de substâncias e de aditivos (usualmente } \\
\text { com muitos ingredientes em sua composição), } \\
\text { visando conservar e/ou modificar cor, odor, } \\
\text { sabor ou textura do produto final }\end{array}$ & $\begin{array}{l}\text { nuggets, néctar de } \\
\text { frutas, margarina, } \\
\text { refrigerantes e } \\
\text { macarrão instantâneo }\end{array}$ \\
\hline
\end{tabular}

Tabela 1. Escala de processamento de alimentos. Fonte: Adaptado pelos autores, a partir da escala apresentada pelo NUPENS.

Em 2014, a classificação NOVA embasou as recomendações da segunda edição do Guia Alimentar para a População Brasileira, dando início à atual disputa por dominância do consumo alimentar brasileiro, principalmente devido à criação do Grupo 4, apresentado na tabela 1: alimentos ultraprocessados. A controvérsia analisada neste artigo refere-se a um dos momentos de pico desse embate.

Os ultraprocessados são demonizados por personalidades ligadas ao universo da gastronomia, que proliferam na TV brasileira e em canais do YouTube sobre comida. Chefs de cozinha como Bela Gil ${ }^{6}$ e Rita Lobo7, alçadas à condição de estrelas midiáticas, defendem a dieta natural como a mais saudável para o consumo contínuo e de longo prazo. Bela Gil é conhecida por substituir ingredientes para criar versões supostamente mais saudáveis das receitas e pelo incentivo na compra de produtos orgânicos e de pequenos

5 Disponível em: <http://www.fsp.usp.br/nupens/>. Último acesso em: 12 mar. 2021.

6 Disponível em: <http://www.belagil.com/>. Último acesso em: 12 mar. 2021.

7 Disponível em: <https://www.panelinha.com.br/>. Último acesso em: 12 mar. 2021. 
produtores. Já Rita Lobo é defensora de alimentos naturais - o que denomina "comida de verdade" - , e argumenta que não se deve consumir produtos ultraprocessados e que a comida deve ser preparada na cozinha de casa. Rita Lobo critica a prática de dietas e advoga, em seus programas na TV ou no YouTube, que comida de pacote não é comida de verdade.

Comer de forma equilibrada, pensando em nutrição e saúde, no entanto, possui variações a depender do enunciador. Para os chefs e jurados do programa Masterchef ${ }^{8}$, veiculado pelo canal de televisão aberta Bandeirantes e com reprises na TV por assinatura, comer está ligado ao prazer, ao sensorial, à experiência dos comensais e, ao mesmo tempo, a um senso de responsabilidade e estudo constante. Existem muitos outros programas desse tipo de talent show gastronômico na grade dos canais abertos, mas principalmente na TV paga. Existe até mesmo um canal exclusivo sobre comida, com 24 horas de programação, o Food Network ${ }^{9}$.

Dentre os adversários dos alimentos ultraprocessados, além dos chefs, podemos citar entidades como a Aliança pela Alimentação Adequada e Saudável, a Aliança de Controle do Tabagismo (ACT) e o já mencionado NUPENS. O movimento slow food pode ser considerado outro adversário dos ultraprocessados, pois seus adeptos valorizam os ingredientes naturais e prezam pelo comer junto, sem pressa, apreciando o momento em um certo "retorno às origens, à natureza, aos sentimentos e sensações humanas dentro de um tempo espiralado, que alia desenvolvimento tecnológico à retomada de valores arcaicos" (PERES-NETO; HADLER, 2016, p. 259). A dimensão comunitária, o hedonismo e o cultivo de produtos locais, com a valorização do que é artesanal, também são características do movimento.

Em oposição aos chefs, movimento slow food e entidades como o NUPENS, estão as indústrias de alimentos, associações por elas financiadas e representantes da cadeia produtiva do agronegócio. O site Alimentos Processados ${ }^{10}$ — iniciativa do Instituto de Tecnologia de Alimentos (ITAL) ${ }^{11}$, vinculado à Agência Paulista dos Agronegócios (APTA) e à Secretaria de Agricultura e Abastecimento do Estado de São Paulo — divulga informações sobre o setor

8 Disponível em: <https://entretenimento.band.uol.com.br/masterchef/>. Último acesso em: 12 mar. 2021.

9 Disponível em: <https://www.discoverybrasil.com/foodnetwork>. Último acesso em: 12 mar. 2021.

10 Disponível em: <http://alimentosprocessados.com.br/>. Último acesso em: 12 mar. 2021.

11 Disponível em: <http://www.ital.sp.gov.br/>. Último acesso em: 12 mar. 2021. 
industrial de alimentos, comunicando à população que seus produtos são confiáveis e que há uma vasta quantidade de mitos e preconceitos acerca do alimento industrialmente processado, tais como os de que alimentos processados não oferecem benefícios aos consumidores; não são saudáveis; não são nutritivos; possuem aditivos maléficos à saúde.

O referido site noticia também que o preparo de qualquer alimento nos lares ou em estabelecimentos comerciais já o configuraria como processado, seja um cozimento ou mesmo uma filtragem. Nessa perspectiva, um bolo de fubá, elaborado a partir de ingredientes como ovos, açúcar, fubá, farinha de trigo, óleo, leite e fermento em pó, seria um alimento ultraprocessado, por possuir muitos ingredientes e não por causa da "quantidade de aditivos químicos que o insumo alimentar recebe para que seja transformado em produtos atrativos e de valor comercial" (FREITAS; TRINDADE, 2016, p. 213). Aditivos como corantes artificiais e ingredientes sintéticos, que visam prolongar a vida útil dos alimentos, pouco preservam o natural do alimento.

Trata-se da natureza modelada na cultura e refeita por meio da técnica, conforme Rabinow (1999). Uma vez que a natureza é continuamente modificada de acordo com diretrizes industriais, "ela pode ser definida e refeita para satisfazer outras especificações biopolíticas, como nutrição" (RABINOW, 1999, p. 150), para a qual o valor do alimento ultraprocessado é aferido não só por quanto ele pode emular o não processado, "mas também em termos do valor para a saúde dos ingredientes de seus componentes - vitaminas, colesterol, fibra, sal" (RABINOW, 1999, p. 150). O autor complementa esse raciocínio ponderando que alguns desses alimentos ultraprocessados podem ser alternativas até mesmo superiores aos naturais.

Nesse sentido, os que defendem algum nível de consumo de ultraprocessados na dieta da população brasileira alegam que todos os grupos alimentares devem compor a dieta diária, sendo a diversidade de alimentos e o equilíbrio/ moderação no consumo as bases para uma alimentação saudável. Outro argumento que merece destaque reside no fato de que os alimentos industrialmente processados atendem aos requisitos de segurança alimentar e, principalmente, de segurança do alimento. Conforme Spers, Zylbersztajn e Machado Filho (2004), segurança alimentar refere-se ao abastecimento suficiente determinado a uma população. Já segurança do alimento diz respeito a ter a garantia de que o alimento ingerido não irá causar problemas de saúde a quem o consumir. Por exemplo, a segurança de que não haverá 
uma intoxicação alimentar ao comer uma margarina que estiver devidamente refrigerada e dentro do prazo de validade. Aspecto que, de acordo com essa visão, os alimentos de produção artesanal não podem assegurar, pois uma manteiga artesanal comprada diretamente de um pequeno produtor rural ou uma manteiga clarificada feita por um vizinho estará sujeita a toda sorte de contaminações (bactérias, fungos, fragmentos de insetos, entre outros), por não passar por processos controlados de higienização que a indústria alimentícia dispõe, como a pasteurização do leite.

\section{Consumo alimentar sob uma mirada biopolítica}

O poder exercido ao nível da vida, conforme Rabinow e Rose (2006), já era algo teorizado por Foucault no seu diagrama bipolar - que Pelbart (2011) nomeia de tecnologia de dupla face a caracterizar o biopoder. Um lado é constituído pela anátomo-política do corpo humano e, no polo inverso, os controles reguladores de uma biopolítica da população. Dessa forma, o biopoder engloba estratégias e contestações sobre vitalidade e mortalidade: "enquanto o poder soberano faz morrer e deixa viver, o biopoder faz viver e deixa morrer. Dois regimes, duas lógicas, duas concepções de morte, de vida, de corpo" (PELBART, 2011, p. 55). Assim, o poder produz e ordena forças, mais do que as destrói.

Ao analisar o conceito de poder em Foucault, Rose (2011) aponta que esse constructo opera no âmbito da subjetividade e permeia todas as práticas. Nesse sentido, as pessoas são regidas ou passam a regular as suas próprias ações com base na governamentalidade hegemônica. Em outras palavras,

[...] a subjetivação é, assim, o nome que se pode dar aos efeitos de composição e recomposição de forças, práticas e relações que se esforçam ou operam para transformar o ser humano em diversas formas de sujeito, que sejam capazes de se constituir em sujeitos de suas próprias práticas, bem como das práticas de outros sobre eles. (ROSE, 2011, p. 236-237).

A esfera do consumo alimentar é um palco em que esses efeitos de composição e recomposição são visibilizados. Afinal, basta notar que não precisamos de incentivos governamentais explícitos para buscar o que consideramos hábitos saudáveis na nossa alimentação diária. Com efeito, os regimes de convocação se dão na ordem da autonomia regulada (ROSE, 2011). Segundo Prado (2013), a convocação promove mais do que uma satisfação 
de necessidade, mas principalmente conforma uma demanda latente que se expressa em um querer cultural. Assim, cada querer possui suas respectivas convocações, com seus discursos modalizadores biopolíticos e enunciadores específicos, em dispositivos com contratos comunicacionais compatíveis em uma combinação maleável de agentes, técnicas e imagens. Portanto,

[...] a escolha do consumidor pode se alinhar com objetivos macroeconômicos e vantagens de negócios: a vida econômica pode ser governada e as aspirações empresariais realizadas através das escolhas feitas por consumidores em suas buscas por realização pessoal. (ROSE, 2011, p. 226).

Nessa perspectiva, Sibilia (2015) argumenta que o capitalismo contemporâneo - em que o capital financeiro se sobrepõe ao produtivo - metaboliza forças vitais cada vez mais sutis e menos evidentes para ofertar produtos, serviços e subjetividades. Tanto Sibilia (2015) quanto Prado (2013) descortinam características da sociedade de controle (DELEUZE, 1992), a qual, na contemporaneidade, manifesta-se na lógica neoliberal da vitalidade (RABINOW; ROSE, 2006): cuidados com a saúde, exercícios e alimentação, arregimentados por grandes corporações com o objetivo de angariar mercados e potencializar lucros.

Tal lógica modela e agencia os indivíduos na constituição de suas autonarrativas e também coaduna regimes enunciativos e práticas discursivas que variam de lugar para lugar. Na alimentação, Ortiz aborda essa questão por meio da difusão espacial e da tradição alicerçada no tempo. Desta feita, "a alimentação revela ou preserva os costumes, localizando-os em suas respectivas culturas. Ela traduz a estabilidade do grupo social" (ORTIZ, 2007, p. 77). No processo de mundialização, conforme o autor, a comida deixa de ser um abrigo frente à fragmentação e à aceleração da pós-modernidade, entre outros fatores, por causa da alimentação industrialmente processada que rompe a relação entre lugar e alimento. Esse tipo de comida supriu necessidades vitamínicas e minerais de grandes contingentes populacionais, ao mesmo tempo em que colaborou com o aumento da obesidade em países com hábitos culinários tradicionalmente diversos, como os EUA e o Brasil.

\section{O caso da nota técnica do Ministério da Agricultura, Pecuária e Abastecimento}

Um capítulo importante do embate alimentos naturais versus (ultra)processados aconteceu em 14 de setembro de 2020 e nos dias subsequentes, quando 
o Ministério da Agricultura, Pecuária e Abastecimento (MAPA) requisitou uma reformulação do Guia Alimentar para a População Brasileira por meio da nota técnica $n^{\circ} 42 / 2020^{12}$, cujo conteúdo ecoou fortemente em diversos públicos relacionados à alimentação e à saúde pública. A partir daí, o magma da controvérsia entrou em ebulição. De um lado, o NUPENS — que elaborou o referido guia - e associações como a Aliança pela Alimentação Saudável e o Instituto Brasileiro de Defesa do Consumidor (IDEC). De outro, favorável à revisão do guia, a Sociedade Brasileira de Alimentação e Nutrição (SBAN) e a Associação Brasileira da Indústria de Alimentos (ABIA), entre outros. Essas entidades foram selecionadas para compor o corpus (além do próprio ministério), pois emitiram comunicados oficiais de diferentes naturezas, de notificações extrajudiciais a manifestos. Conforme veremos, cada entidade possui suas nuances mais ou menos radicais no espectro da controvérsia.

Na nota técnica do MAPA, destacam-se trechos do atual Guia Alimentar para a População Brasileira, nos quais é abordada a importância do documento para promover a saúde e a segurança alimentar da população, e, na sequência, são apresentadas críticas em relação à excessiva ênfase dada, no guia, ao tipo de processamento dos alimentos e às quatro categorias de classificação, que enumeramos na tabela 1 deste artigo. Afirma-se, também, que essa classificação é confusa e incoerente, que prejudica a implementação de diretrizes de políticas públicas e que a própria definição de alimento ultraprocessado parece ser algo cômico, seja pela contagem de ingredientes, seja pela indicação do guia para que os consumidores fiquem atentos a nomes pouco familiares nos rótulos (como dica para evitar o consumo de alimentos). Por fim, são citados estudos científicos que balizariam os argumentos em favor dos ultraprocessados como parte da dieta da população.

\section{Cartografia da controvérsia: reverberações da nota técnica do MAPA}

Conforme Venturini (2010), as controvérsias retratam o social tal qual pedras em estado de magma, sendo líquidas e sólidas simultaneamente. Assim, 
do fluxo, a lava esfria e se cristaliza, alguma outra rocha sólida tocada pelo calor do fluxo derrete e se torna parte do fluxo. A mesma flutuação entre diferentes estados de solidez pode ser observada nas controvérsias. Por meio dessa dinâmica, o social é incessantemente construído, desconstruído e reconstruído. Este é o social em ação e é por isso que não temos outra escolha a não ser mergulhar no magma. (VENTURINI, 2010, p. 264).

Nesse sentido, para captar os diferentes estados de liquefação do social, é que destacamos como procedimentos de análise: (i) levantamento e seleção das reações de entidades ligadas ao setor alimentício, (ii) a quantificação da repercussão nas fanpages dessas mesmas associações e também do ministério e (iii) a categorização dos comentários em redes discursivas.

A ABIA, como principal representante das indústrias alimentícias, alega, em sua nota oficial ${ }^{13}$, que a constante revisão de um guia alimentar é uma boa prática para que se esteja alinhado aos avanços da ciência, ressaltando a importância da industrialização para atender as demandas do consumidor. O comunicado apontou falhas na atual edição do guia alimentar, pois, para esta associação, não existe alimento bom ou ruim, e o principal é o consumo equilibrado de todos os tipos. Ao final, citam um ranking espanhol, no qual o Guia Alimentar da População Brasileira aparece como um dos piores do mundo.

A SBAN salienta, em sua publicação ${ }^{14}$, que são recomendáveis revisões periódicas dos guias alimentares de cada país e que a atual versão do guia nacional já tem muitos anos. Defende que a revisão precisa envolver vários atores (academia, governo, profissionais de saúde etc.) com visão científica.

No outro lado do espectro dessa controvérsia, o IDEC divulgou uma notificação extrajudicial ${ }^{15}$ em que pede esclarecimentos ao MAPA sobre o conteúdo de sua nota técnica, pois, de acordo com o instituto, o documento do MAPA vai contra o interesse público, as evidências científicas e os fundamentos 
legais. Além disso, ressalta que o órgão acompanhou todo o desenvolvimento do guia, criado pelos pesquisadores do NUPENS com a colaboração da Organização Pan-Americana da Saúde (OPAS), e destaca reconhecimento internacional do guia por parte de entidades como a Organização Mundial da Saúde (OMS), a Organização das Nações Unidas para Alimentação e Agricultura (FAO) e o Fundo das Nações Unidas para a Infância (Unicef). O IDEC salienta, também, que a classificação em níveis de processamento é a correta para combater a obesidade e as doenças crônicas que essa condição provoca. Por fim, aponta a fragilidade dos argumentos e das referências científicas apresentadas, levantando "suspeitas de grave interferência de entidades privadas do setor produtivo na construção do ato administrativo em questão emanado por agentes públicos do MAPA, o que pode configurar atos de improbidade puníveis conforme artigo 4 da Lei n 8429/1992".

A Aliança pela Alimentação Adequada e Saudável emitiu um manifesto ${ }^{16}$, coletando assinaturas em defesa do guia, porque entende que ele estaria sob ataque. O objetivo dessa investida seria ocultar os impactos negativos que os alimentos ultraprocessados gerariam na saúde da população brasileira. De modo geral, os argumentos são parecidos com os do IDEC, principalmente no que se refere à falta de evidências científicas que fundamentem a nota técnica do MAPA, bem como na menção aos organismos internacionais que referendam o conteúdo do guia. Vale destacar as menções sobre a necessidade urgente, frente a pandemia do coronavírus, de sistemas alimentares que promovam a alimentação saudável — direito que está na constituição federal.

Por sua vez, o NUPENS, órgão responsável pela elaboração do guia em 2014, juntamente com o Ministério da Saúde, não se furtou ao direito de responder, também por meio de nota oficial ${ }^{17}$. Após apresentar trechos da nota técnica do MAPA - e até destacar benefícios do processamento, como ampliar a validade de certos alimentos - , a entidade tratou de refutar os argumentos da referida nota, ao enfatizar a falta de rigor científico e a ausência de pesquisas (revisões sistemáticas e estudos clínicos). O NUPENS termina sua nota convocando o Ministério da Saúde e a sociedade civil a responderem

16 Nota oficial da Aliança pela Alimentação Adequada e Saudável. Disponível em: <https://www. facebook.com/aliancapelaalimentacao/photos/a.148381815626432/990053594792579/>. Último acesso em: 12 mar. 2021.

17 Nota oficial do Núcleo de Pesquisas Epidemiológicas em Nutrição e Saúde (NUPENS). Disponível em: <https://www.facebook.com/usp.nupens/photos/a.376040909127696/3295126363885788/>. último acesso em: 12 mar. 2021. 
ao que é descrito como um "descabido ataque à saúde e à segurança alimentar e nutricional do nosso povo".

Essas notas de resposta aconteceram nos dias subsequentes, especialmente nos dias 16 e 17 de setembro de 2020. Somente em 18 de setembro, o MAPA publicou algo relacionado ao assunto em sua fanpage ${ }^{18}$. Até então, o ministério havia postado conteúdos sobre a estimativa do valor bruto da produção agropecuária de 2020 no valor de R\$771,4 bilhões, sobre o Zoneamento Agrícola de Risco Climático (Zarc), sobre o selo arte para produtos artesanais que o queijo serrano produzido no estado de Santa Catarina recebeu, sobre a produção de kombucha no Brasil e sobre a primeira exportação brasileira de melões para a China. Quanto ao que foi denominado nota de esclarecimento, o MAPA afirmou que não encaminhou ao Ministério da Saúde solicitação de alteração no guia de 2014, que o documento vazado estava sendo debatido internamente e que as discussões ainda estavam em estágio inicial.

A esses rastros digitais das entidades, somam-se outros das interações dos sujeitos nas e com as redes sociais, "onde toda ação deixa um rastro potencialmente recuperável, constituindo um vasto, dinâmico e polifônico arquivo de nossas ações" (BRUNO, 2012, p. 684), pegadas que, ao mesmo tempo, configuram duração e efemeridade, num limiar entre presença e ausência. Segundo Bruno (2012), essa conceituação de rastros é baseada na TAR, que os concebe como inscrições de ações - quando existe ação, haverá rastro -, sendo a rede aquilo que faz proliferar mediadores e não a interpretação destes como prova ou evidência, e que compreende a rede como aparato de captura - concepção empregada no marketing digital ou em investigações criminais.

A tabela 2 reúne os números de interações nas fanpages do ministério e nas páginas das referidas associações. Em todos os casos, foi selecionado somente o primeiro post sobre o assunto em cada uma das seis páginas no Facebook. Isso porque algumas dessas entidades publicam com frequência materiais sobre a questão alimentar, principalmente NUPENS, ABIA e Aliança pela Alimentação Adequada e Saudável. 


\begin{tabular}{|l|l|l|l|l|l|l|}
\hline \multirow{2}{*}{ Interações } & \multicolumn{2}{|l|}{ Pró-revisão do guia } & \multicolumn{2}{l|}{ Contra a revisão do guia } \\
\cline { 2 - 8 } & MAPA & ABIA & SBAN & NUPENS & IDEC & $\begin{array}{c}\text { Aliança pela } \\
\text { alimentação }\end{array}$ \\
\hline Curtidas & 106 & 3900 & 10 & 409 & 164 & 332 \\
\hline Amei & 2 & 25 & 0 & 143 & 11 & 4 \\
\hline Força & 0 & 2 & 0 & 4 & 1 & 2 \\
\hline Risada & 0 & 16 & 0 & 1 & 0 & 0 \\
\hline Espanto & 0 & 2 & 0 & 10 & 0 & 1 \\
\hline Bravo & 3 & 73 & 0 & 3 & 0 & 49 \\
\hline Triste & 0 & 5 & 2 & 4 & 1 & 49 \\
\hline Compartilhamentos & 32 & 36 & 3 & 753 & 127 & 781 \\
\hline $\begin{array}{l}\text { Comentários } \\
\text { pró-guia }\end{array}$ & 2 & 36 & 0 & 49 & 1 & 39 \\
\hline contra o guia & 0 & 4 & 0 & 0 & 1 & 0 \\
\hline
\end{tabular}

Tabela 2. Manifestações favoráveis e contrárias à revisão do guia. Fonte: Dados coletados pelos autores nas fanpages das entidades.

De modo geral, nota-se que os compartilhamentos e comentários positivos foram mais volumosos no grupo que defende o guia. Além disso, as três entidades favoráveis obtiveram a segunda, terceira e quarta posição em curtidas. Curiosamente, o post na página da ABIA recebeu muito mais curtidas do que todas as demais reunidas, o que não se manteve nas outras reações.

Outra interação dessa entidade a se destacar foi a que mostra o emoji bravo com o conteúdo da postagem, além do número de comentários favoráveis ao guia. Nas reações às postagens de outras entidades, houve pouco comentário invertido, isto é, entidade pró-guia e muitos comentários contrários e vice-versa. A reação de braveza também foi alta na fanpage da Aliança pela Alimentação Adequada e Saudável. A hashtag \#euapoiooguiaalimentar ou similares foram as mais empregadas nos comentários. Ao relacionar esse dado com a quantidade de comentários pró-guia, compreende-se que a maior parte dos sujeitos está descontente com a ameaça de revisão do guia. As interações com os emojis de coração (amei) e de cara de espanto, além do alto número de compartilhamentos e de comentários, são um sinal de que 
o coletivo que acessa a página do NUPENS tem a entidade em alta conta, retratando a constância com que a fanpage aborda a temática da alimentação natural versus ultraprocessada, com argumentos favoráveis à comida natural.

Além disso, foi possível observar o arranjo social enquanto dinâmica, com suas relações de poder e sentidos cristalizados, na formação de redes discursivas que agrupamos nas seguintes categorias ${ }^{19}$ :

- Econômico - postagens contrárias aos alimentos ultraprocessados, enfatizando os lucros oriundos deste tipo de comida, como: “Claro que apoia! Lucrar com a produção de ultraprocessados é o principal objeivos de grande parte da indústria de alimentos e bebidas. Queria que apoiassem assim a elaboração de rótulos mais simples e informativos para a população..."; "Óbvio que vocês apoiam. O intuito e lucro e jogar produto na mesa das famílias de péssima qualidade nutricional".

- Político - comentários que apontam o viés político e os interesses envolvidos, por exemplo: "Conflitos de interesse, o Guia não tem nada que bote defeito nele!"; “Gostaria de saber por quem isso é patrocinado. Aí daria pra entender o 'posicionamento'."

- Qualidade do guia - posts com conteúdo que enaltece o fundamento científico e/ou a utilidade do Guia Alimentar para a População Brasileira, por exemplo: "Sempre defenderei e perpetuarei os conhecimentos embasados cientificamente do nosso Guia Alimentar, que é referência mundial!"; “Estava aguardando esse posicionamento a respeito dessa ferramenta incrível e inspiradora, acessível e qualificadora, embasada e valorizadora da nossa cultura alimentar !!!!! Abaixo essa nota técnica sem cabimento algum !!!!!!!!!".

- Alimento - comentários sobre os alimentos em si, normalmente desqualificando os ultraprocessados, por exemplo: “Não vamos esmorecer. Vamos fazer a nossa parte, que é evitar ao máximo o consumo de processados e ultraprocessados. Assim a indústria de comida porcaria terá que rever suas formulações e condutas".

Vemos, desse modo, uma teia de agenciamentos sociotécnicos revelando uma dimensão biopolítica, tal qual enunciado no diagrama bipolar de Foucault (RABINOW; ROSE, 2006), tanto no nível do indivíduo quanto no dos controles reguladores da população. Afinal, entidades conhecidas, pessoas 
anônimas, dados estatísticos e/ou as redes sociais possuem capacidade de agência, pois, enquanto actantes, não são meros intermediários que somente registram e transmitem informações, mas fazem diferença nas associações. Primo (2012) exemplifica esse ponto da seguinte forma: uma conversa entre dois colegas de trabalho por e-mail seria diferente se fosse mantida via redes sociais, como o Facebook na controvérsia analisada neste artigo. Assim, a TAR nivela atores humanos e não-humanos, de modo que "a continuidade de um curso de ação raramente consiste em conexões entre humanos (para as quais, de resto, as habilidades sociais básicas seriam suficientes) ou entre objetos, mas, com muito maior probabilidade, ziguezagueia entre umas e outras" (LATOUR, 2012, p. 113). É pertinente ressaltar que não se está defendendo que humanos e não-humanos sejam iguais em todos os sentidos, mas que, ao serem colocados em um mesmo plano, evidenciam-se suas particularidades e hibridismos.

Outro traço da teoria ator-rede que se pode vislumbrar aqui é o caráter efêmero das associações e de suas redes de interações, ou, em outras palavras, como a rocha líquida do magma se solidifica. Isto porque verificou-se que, antes da virada do mês, os comentários já haviam praticamente cessado, conforme demonstrado na figura 1.

\begin{tabular}{l|l} 
guia alimentar & + Comparar
\end{tabular}

Brasil - $01 / 09 / 2020-30 / 09 / 2020$ Todas as categorias - Pesquisa na Web -

Interesse ao longo do tempo (2) $\quad \downarrow\langle\rangle<$

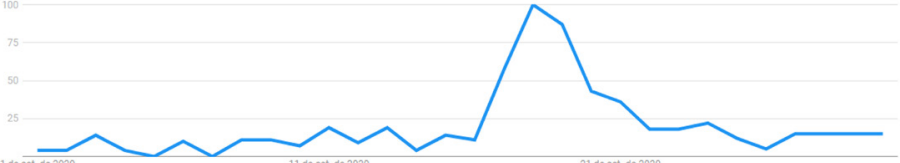

Figura 1. Gráfico feito pelos autores, a partir da ferramenta Google Trends - período pesquisado de $1^{\circ}$ set. 2020 a 30 set. 2020. Fonte: Google Trends.

De acordo com Santaella e Cardoso (2015), quando são analisadas as interações, o foco recai no movimento, em perceber não como os atores se adequam às estruturas, mas sim as maneiras pelas quais as estruturas são forjadas pelos atores. Assim, as interações conferem poder às associações 
ator-rede formadas por muitos mediadores e poucos intermediários, segundo preconiza a sociologia das associações, uma vez que mediadores engendram outros mediadores (LATOUR, 2012), o que pode dar rumos imprevisíveis às controvérsias. Desse modo,

quando entendemos ainda que as redes não estão jamais acabadas, sendo elas menos a coisa descrita do que o processo de descrição, retraçar os rastros digitais que as compõem é uma tarefa simultaneamente cognitiva e política. O "social", diria Latour, se constitui precisamente nesses movimentos intermitentes, é aí que fazemos sociedade, mundos. (BRUNO, 2012, p. 700).

Assim, mesmo concentradas em um curto intervalo, as interações tiveram um impacto biopolítico e social relevante, pois, se o embate legitimasse a nota técnica do MAPA, a proposta poderia seguir adiante e interferir nas vidas de toda a população brasileira e ao mesmo tempo na própria constituição dos sujeitos. Essa interferência poderia ter impactos negativos evidentes, como aumento nos índices de doenças crônicas não transmissíveis (DCNT), por exemplo, obesidade e diabetes. Por outro lado, haveria também, surpreendentemente, a possibilidade de termos aspectos positivos. Conforme Reis (2019), o Guia Alimentar para a População Brasileira mostrou-se inócuo na promoção dos hábitos alimentares preconizados no documento em grande parte da amostra, composta por pessoas com sobrepeso ou obesas que usam o serviço público de saúde na região sul da cidade de São Paulo. Ou seja, pelo menos nesse caso pesquisado pela autora, o propósito a que o guia se destina - de comunicar-se diretamente com a população - não foi atingido. Com efeito, compreende-se que o social precisa ser constantemente renegociado (PRIMO, 2012).

O que nos leva à reflexão sobre o cerne da controvérsia: será realmente necessária uma revisão do Guia Alimentar para a População Brasileira? Este artigo não se propôs a responder à questão acima, mas sinaliza a necessidade dessa investigação em estudos futuros, por exemplo, realizando uma análise de conteúdo e/ou discurso em material extraído da atual versão do guia e mesmo nas reverberações aqui levantadas. Outra possibilidade seria uma pesquisa de campo - focus group ou outra modalidade similar de coleta de dados - com pessoas leigas em nutrição para avaliar a efetividade das mensagens que o guia deseja passar à população.

De todo modo, pelos elementos aqui trazidos, não nos parece necessária a revisão do Guia Alimentar para a População Brasileira. Isso porque o 
maior incômodo enfrentado pelas indústrias alimentícias, materializado na nota técnica, é em relação à escala de processamento dos alimentos, particularmente à nomenclatura "ultraprocessados" - que prejudica a imagem desse tipo de alimento e, consequentemente, a lucratividade das empresas. Esses conglomerados ilustram a nova racionalidade da governamentalidade neoliberal (DARDOT; LAVAL, 2016), ao demandarem por um Estado que não interfira excessivamente para não prejudicar a atividade dos agentes econômicos e também que os indivíduos tenham liberdade de escolha sobre o tipo mais apropriado de alimentação, mesmo que não entendam sobre nutrição.

Afinal, o discurso neoliberal homogeneiza os discursos em favor dos detentores do capital, buscando, na contemporaneidade, mais do que tornar os corpos dóceis, promover agenciamentos que resultem na produção de formas mais eficazes de sujeição. “O capitalismo transforma o não-capital em capital, não só paisagens, ritmos, mas também maneiras de ser, de fazer, de ter prazer, atitudes, e nisso consiste sua inventividade nos últimos anos" (PELBART, 2011, p. 104). A inovação da tecnologia neoliberal reside em associar a maneira com que o sujeito é governado à maneira com que o próprio indivíduo se governa (DARDOT; LAVAL, 2016). Desta feita, a nova racionalidade vai até o aspecto mais íntimo do indivíduo, ou seja, a racionalização do desejo.

O Guia Alimentar para a População Brasileira é, portanto, um mecanismo de poder em disputa, é um saber que produz e ordena forças - abarca relações e efeitos de poder (FOUCAULT, 2015) - e interfere nos ordenamentos do social.

\section{Considerações finais}

A questão que norteou este artigo versa sobre o processo de abertura e fechamento da caixa-preta em relação ao pedido de reformulação do Guia Alimentar para a População Brasileira. Com efeito, pode-se observar as estratégias dos atores na construção de uma rede e perceber como a caixa-preta foi fechada e, mesmo após o fechamento dessa controvérsia específica, foi possível recuperar sua constituição. Nota-se que as disputas discursivas pelo consumo de alimentos são mediadoras nesse contexto, que nos ajuda a entender as relações entre sujeitos e entidades e, em segunda ordem, dos sujeitos com as corporações alimentícias. “Descrever essas tramas é produzir um conhecimento sobre um fenômeno social qualquer e, ao mesmo tempo, 
reinventar um espaço político" (BRUNO, 2012, p. 700). Essas mediações operam de forma polêmica, emergindo das ações em rede e trazendo em sua trama dimensões políticas, econômicas e culturais do consumo alimentar.

De acordo com o exposto, depreende-se que a questão de controle é imperativa para a formação de uma controvérsia. No caso, controle sobre as lógicas de produção, comunicação e consumo, alinhado a objetivos macroeconômicos. É evidente que as empresas do setor não ficam satisfeitas com ações que reduzam o consumo e/ou enfraqueçam suas ações persuasivas de marketing (SANTANA et al., 2020) e, consequentemente, diminuam os lucros gerados pelos alimentos ultraprocessados. Para que se tenha uma ideia do porte dos investimentos das indústrias alimentícias, o estudo de Kelly et al. (2019), realizado em 22 países, tendo representantes da Ásia, África, Europa e Américas, identificou que os alimentos ultraprocessados são os produtos mais presentes na publicidade televisiva.

Se o consumo de alimentos representa simbolicamente os modos dominantes de uma sociedade (ORTIZ, 2007), então a alimentação revela muito sobre a estrutura da vida cotidiana e acerca da constituição dos sujeitos. Conforme Martinelli e Silva (2019), a comida altera a nossa cosmovisão do mundo, pois, quando se modifica a alimentação, altera-se o sujeito. Desse modo, um documento oficial balizador de políticas públicas, como o Guia Alimentar para a População Brasileira, que preconiza ingestão zero ou muito próxima desse número para o alimento ultraprocessado, torna-se passível de sofrer retaliações das mais diversas por meio de convocações biopolíticas de empresas, as quais acabam reverberando midiaticamente.

Pelbart (2011) argumenta que jamais tivemos algo que englobasse a totalidade da existência humana: corpos, mentes, afetos, subjetividades, como o que ocorre na era do capitalismo conexionista/rizomático. Contudo, o autor corrobora as ideias de Foucault no entendimento de que, para toda dominação, existe a respectiva insubordinação (biopotência) e que a principal luta é aquela contra as formas de assujeitamento. Nesse sentido, a controvérsia analisada suscita conformidade e, ao mesmo tempo, ruptura, já que as manifestações favoráveis e contrárias ao guia alimentar foram significativas.

A situação observada, portanto, evidencia uma construção social coletiva por parte dos apoiadores do guia, que permitiu a emergência de deslocamentos nas relações de poder, impedindo a continuidade da tramitação da nota técnica do MAPA. A resistência aos mecanismos de poder apregoada 
por Foucault pode vir por meio da alimentação. Assim, o que se come e bebe pode transformar não apenas a forma física ou a saúde individual. Eis aqui uma evidência de biopotência: a possibilidade de desvio do estabelecido e de emergência de outras formas de viver. Nesse sentido, se a controvérsia estudada possibilita modificações e também acomodações em relação ao consumo alimentar, haverá também espaço para que o sujeito/consumidor avalie suas escolhas e se reinvente.

Lucas de Vasconcelos Teixeira é doutorando do Programa de Pós-Graduação em Comunicação e Práticas de Consumo da ESPM e bolsista CAPES-PROSUP. É integrante do grupo de pesquisa em Comunicação, Discursos e Biopolíticas do Consumo - BIOCON (ESPM/CNPq).

Ivteixeira@gmail.com

Tânia Márcia Cezar Hoff é professora titular do Programa de Pós-Graduação em Comunicação e Práticas de Consumo (ESPM). É doutora pela Universidade de São Paulo e pós doutora pela PUC-SP. É coordenadora do grupo de pesquisa em Comunicação, Discursos e Biopolíticas do Consumo - BIOCON (ESPM/CNPq).

thoff@espm.br

Contribuições de cada autor: Lucas: escrita - primeira redação, revisão e edição; fundamentação teórica e conceituação; curadoria de dados; investigação de campo; metodologia; análise formal do corpus; Tânia: revisão e edição; supervisão e gestão do projeto de pesquisa; fundamentação teórica e conceituação; curadoria de dados; metodologia; análise formal do corpus.

\section{Referências}

BRUNO, F. Rastros digitais sob a perspectiva da teoria ator-rede. Revista Famecos, v. 19, n. 3, 2012, p. 681-704.

DARDOT, P.; LAVAL, C. A nova razão do mundo: ensaio sobre a sociedade neoliberal. São Paulo: Boitempo, 2016. 
DELEUZE, G. Conversações (1972-1990). São Paulo: Editora 34, 1992.

FOUCAULT, M. Microfísica do poder. Rio de Janeiro: Paz e Terra, 2015.

FREITAS, A.; TRINDADE, E. A economia e o consumo midiatizado das marcas de alimentos e bebidas globais: algumas considerações. Revista Communicare. v. 16. n. 2, 2016, p. 210-228.

JAMESON, F. Pós-modernidade e sociedade de consumo. Novos Estudos CEBRAP, n. 12, 1985, p. 16-26.

KELLY, B. et al. Global benchmarking of children's exposure to television advertising of unhealthy foods and beverages across 22 countries. Obesity Reviews, v. 20, 2019, p. 116-128.

KUMAR, K. Da sociedade pós-industrial à pós-moderna: novas teorias sobre o mundo contemporâneo. Rio de Janeiro: Jorge Zahar, 2006.

LATOUR, B. Reagregando o social: uma introdução à teoria ator-rede. Salvador: Edufba; São Paulo: Edusc, 2012.

LEMOS, A. A comunicação das coisas: teoria ator-rede e cibercultura. São Paulo: Annablume, 2013.

MARTINELLI, F.; SILVA, J. G. X. Comida como afeto: identidades, emoções e alteridade na produção e no consumo alimentar. In.: SIQUEIRA, D.; FORTUNA, D. (Orgs.). Narrativas do Eu: gênero, emoções e produção de sentidos. Porto Alegre: Sulina, 2019. p. 246-264.

MONTEIRO, C. A. et al. A new classification of foods based on the extent and purpose of their processing. Cadernos de saúde pública, v. 26, n. 11, 2010, p. 2039-2049.

ORTIZ, R. Mundialização e cultura. São Paulo: Brasiliense, 2007.

PELBART, P. Vida capital. São Paulo, Iluminuras, 2011.

PERES-NETO, L.; HADLER, R. Ética e comunicação das escolhas alimentares: uma análise da tribo pós-moderna do Slow Food. Razón y Palabra, v. 20, n. 3-94, 2016, p. 248-263.

PRADO, J. L. A. Convocações biopolíticas dos dispositivos comunicacionais. São Paulo: EDUC-Fapesp, 2013.

PRIMO, A. O que há de sociais nas mídias sociais? Reflexões a partir da Teoria Ator-Rede. Contemporânea Revista de Comunicação e Cultura, v. 10, n. 3, 2012, p. 618-641.

RABINOW, P. Artificialidade e iluminismo: da sociobiologia à biossociabilidade. In: RABINOW, P. Antropologia da Razão. Rio de Janeiro: Relume-Dumará, 1999. p. 135-157.

; ROSE, N. O conceito de biopoder hoje. Revista de Ciências Sociais, v. 11. n. 1, 2006, p. 27-57. 
REIS, D. S. M. Guia alimentar para a população brasileira: deficiências no diálogo entre o Estado e a sociedade. In: MATOS, H.; GIL, P. Comunicação, políticas públicas e discursos em conflito. São Paulo: ECA-USP, 2019. p. 77-117.

ROSE, N. Agenciando nossos selfs. In: ROSE, N. Inventando nossos selfs: psicologia, poder e subjetividade. São Paulo: Vozes, 2011, p. 234-273.

SANTAELLA, L.; CARDOSO, T. O desconcertante conceito de mediação técnica em Bruno Latour. Matrizes: Revista do Programa de Pós-Graduação em Ciências da Comunicação da USP, v. 9, n. 1, 2015, p. 167-185.

SANTANA, M. O. et al. Analysing persuasive marketing of ultra-processed foods on Brazilian television. International Journal of Public Health, v. 65, n. 7, 2020, p. 1067-1077.

SIBÍLIA, P. O homem pós-orgânico: a alquimia dos corpos e das almas à luz das tecnologias digitais. Rio de Janeiro: Contraponto, 2015.

SPERS, E. E.; ZYLBERSZTAJN, D.; MACHADO FILHO, C. A. P. O papel público e privado na percepção do consumidor sobre a segurança dos alimentos. Impulso UNIMEP, v. 15, n. 36,2004 , p. 49-57.

VENTURINI, T. Diving in magma: how to explore controversies with actor-network theory. Public Understanding of Science, v. 19, n. 3, 2010, p. 258-273.

Artigo recebido em 23/03/2021 e aprovado em 02/08/2021. 